\title{
Precision Medicine in Europe - Forging a Common Vision
}

\author{
Jose M Martin-Moreno1,2 \\ 1. Professor, Department of Preventive Medicine and Public Health of the Medical School and INCLIVA Clinical Hospital Biomedical Research Institute, \\ University of Valencia, Spain; 2. Senior Associate, Johns Hopkins Bloomberg School of Public Health, Baltimore, US
}

\begin{abstract}
The prospect of achieving truly personalised medicine (or precision medicine) has raised patients' hopes and piqued researchers' curiosity, prompting the development of new -omics fields and attracting interest from the health technology industry. However, to ensure that new advances are incorporated equitably without diverting scarce resources from essential services and underserved populations, European institutions must forge a common policy that balances investments with returns and competition with coordination.

\section{Keywords}

Precision medicine, genomic sequencing, health technology assessments

Disclosure: Jose M Martin-Moreno has no conflicts of interest to declare. No funding was received in the publication of this article. open Access: This article is published under the Creative Commons Attribution Noncommercial License, which permits any non-commercial use, distribution, adaptation and reproduction provided the original author(s) and source are given appropriate credit.

Received: 13 March 2015 Accepted: 19 March 2015 Citation: European Oncology \& Haematology, 2015;11(1):32-3 DOI: 10.17925/EOH.2015.11.01.32 Correspondence: Jose M Martin-Moreno, Department of Preventive Medicine and Public Health of the Medical School and INCLIVA Clinical Hospital Biomedical Research Institute, University of Valencia, Valencia 46010, Spain. E: jose.martin-moreno@uv.es
\end{abstract}

Genomic sequencing has been compared to piecing together a giant biological jigsaw puzzle. It is an arduous, slow process, somewhat prone to error and fraught with technical, practical and ethical complications that make its widespread implementation very challenging for the time being, even in the most advanced healthcare systems. Yet genomic sequencing is simple compared with the broader healthcare aim to which it contributes: personalised medicine, the ability to precisely tailor therapies to the genetic profile of patients and their diseases, thereby increasing efficacy, improving patient outcomes and quality of life and ultimately reducing treatment costs.

This distant endpoint holds so much promise that it is tempting to call for large public and public-private investments, akin to the $\$ 215$ million that President Obama requested of the US Congress in his 2016 budget. ${ }^{1}$ The unwritten rules of globalised one-upmanship would also have Europe match or even surpass the investments of its competitors in scientific innovation to consecrate its place in the vanguard of biomedical and-omics research. However, before the vision of personalised medicine can be fully realised, a host of complex obstacles must be overcome - painstakingly, deliberately and incrementally. European health systems would perhaps be best served by an in-depth situation analysis and a long-term strategy that sets out system goals rooted in equity, patience and proportionality.

Many health system stakeholders, including the European Society of Medical Oncology (ESMO), have speculated on the future of personalised cancer care. ${ }^{2-4}$ The particular relevance of these therapies to oncology is undeniable (as we have seen with new targeted therapies for metastatic breast cancer, ${ }^{5}$ myeloid leukaemia ${ }^{6}{ }^{6}$ melanoma ${ }^{7}$ ) and others, but the oncology community should not underestimate the challenges facing the field, least of all the immense costs and technical demands in collecting, storing and processing the amount of data needed for functional biobanks. The need for researchers to access these data on a large scale raises problems related to equity and distribution of cost burden, as well as privacy and intellectual property. To overcome the technological hurdles, we may need to wait for the development of a whole new field of study - healthcare knowledge engineering - that today is in its infancy. ${ }^{8}$ The regulatory landscape must also be transformed: although market approval for pharmaceuticals is centralised through the European Medicines Agency (EMA), the companion diagnostics are only partially and heterogeneously regulated at a national level, undermining the consistency, comparability and quality of precision diagnostics. Health technology assessments will also undergo a shift in paradigm, for large up-front investments must be weighed against benefits that will be seen only in the long term. In professional training, the sheer speed of progress in the -omics field makes medical curricula obsolete almost as quickly as they are developed; specific to oncology, we know that the genetic profiles of tumours vary widely and evolve over time, creating a possible need for multiple, invasive biopsies among cancer patients, with no assurance or even hope of immediate clinical benefits.

These considerable challenges will be overcome only with time, and progress will be largely incremental, dependent on the gradual maturation of the discipline, emerging technological and computational advances and a sustainable stream of wisely directed research investments. In consideration of the potential epidemiological value of consolidated international biobanks, European countries would be wise to work together. But in light of the high initial costs, it is unrealistic even perverse - to expect the low- and middle-income countries in the east and the south to use scarce resources for this purpose. One widely held conviction, which crystallised in the ESMO Emerging Countries Committee during the 2014 ESMO Conference in Madrid, was that 
resource-strapped countries in Europe, Africa and the Americas could ill afford to pursue precision therapies and should instead concentrate on securing access to essential medicines, basic diagnostic equipment and training. ${ }^{9-10}$ The next stage of personalised medicine should rather be investigated in flagship cancer centres in high-income countries. ${ }^{11}$ Thus, in the context of the real and formidable health inequities persisting throughout Europe and the world, personalised medicine could instead be one more driver of health inequity on a continent that is already plagued by wide gaps in access to quality care.

The ultimate difference, in this as in so many other cases, will be in the leadership shown by national and international bodies, including ministries of health and the European Commission. Specifically, we require a joint strategy on personalised medicine in Europe, developed through a transparent and participatory approach. This roadmap should set out the basic principles and objectives for the -omics fields, including considerations for patient participation and equity. Research investments should be scoped towards the long term, but resource allocation should be proportional to the benefits perceived in the near term and be supported by the same type of economic evaluations to which medicines, surgery and radiotherapy techniques are currently submitted..$^{12}$ Indeed, even the best-supplied health systems in Europe are struggling to finance and provide timely services for citizens; it would be unconscionable to use tax contributions to raise the ceiling on innovation with no certainty about benefits and costs. Only through a common European vision, buttressed by the principles of solidarity, collaboration and good governance, will personalised medicine truly achieve gains for the entire European population.
1. Office of the Press Secretary-White House, Fact sheet: President Obama's Precision Medicine Initiative, 30 Jan 2015. Available at: www.whitehouse.gov/the-pressoffice/2015/01/30/fact-sheet-president-obama-s-precisionmedicine-initiative (accessed 12 May 2015)

2. Ciardiello F, Arnold D, Casali PG, et al., Delivering precision medicine in oncology today and in future-the promise and challenges of personalised cancer medicine: a position paper by the European Society for Medical Oncology (ESMO), Ann Oncol, 2014:25:1673-8.

3. Branzén K. Personalized medicine: a new era for healthcare and industry. Lund, Sweden: Life Science Foresight Institute, 2013

4. Khleif SN, Doroshow JH, Hait WN; AACR-FDA-NCI Cancer Biomarkers Collaborative, AACR-FDA-NCI cancer biomarkers collaborative consensus report: advancing the use of biomarkers in cancer drug development, Clin Cancer Res, 2010;16:3299-318

5. Slamon DJ, Leyland-Jones B, Shak S, et al., Use of chemotherapy plus a monoclonal antibody against HER2 for metastatic breast cancer that overexpresses HER2, N Eng/ J Med, 2001;344:783-92.

6. Hughes TP, Kaeda J, Branford S, et al., Internationa Randomised Study of Interferon versus STI571 (IRIS) Study Group: frequency of major molecular responses to imatinib or interferon alfa plus cytarabine in newly diagnosed chronic myeloid leukemia, N Eng/ I Med, 2003;349:1423-32.

7. Davies H, Bignell GR, CoX C, et al., Mutations of the BRAF Davies H, Bignell GR, CoX C, et al., Mutations of the

8. Beck T, Gollapudi S, Brunak S, et al., Knowledge engineering for health: a new discipline required to bridge the "ICT gap" for health: a new discipline required to bridge the "ICT gap"
between research and healthcare, Hum Mutat, 2012;33:797-802. between research and healthcare, Hum Mutat, 2012;33:797
Magrath I, Adde MA, Overcoming cancer in developing countries; how to improve cancer care, Proceedings of the ESMO 2014 Congress: ESMO Emerging Countries Committee (ECC)—AORTIC-SLACOM-UICC: Personalised medicine with limited resources: Myth or reality?, Ann Oncol, 2014;25(Suppl. 4):iv-40. 10.1093/annonc/mdu316

10. Cazap E, Personalised cancer care: a global perspective, Proceedings of the ESMO 2014 Congress: ESMO Emerging Countries Committee (ECC)-AORTIC-SLACOM-UICC: Personalised medicine with limited resources: Myth or reality? Ann Oncol, 2014;25(Suppl 4): iv-40. 10.1093/annonc/ mdu316.

11. Tannock I, Should personalised medicine be funded in countries with limited resources? Proceedings of the ESMO 2014 Congress: ESMO Emerging Countries Committee (ECC)-AORTIC-SLACOM-UICC: Personalised medicine with limited resources: Myth or reality? Ann Oncol, 2014;25 (Suppl. 4):iv-40. 10.1093/annonc/mdu316.

12. Lievens $Y$, Budget impact vs cost effectiveness: Implications for personalised cancer therapies, Proceedings of the ESMO 2014 Congress: The impact on health services from personalised targeted therapies, Ann Oncol, 2014;25(Suppl 4): iv29-iv30. 10.1093/annonc/mdu308. 